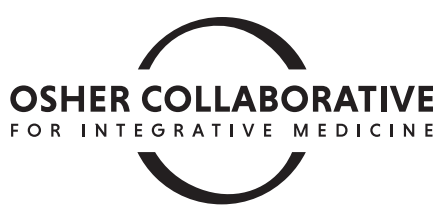

\title{
Nature As Medicine: Mind, Body, and Soil
}

\author{
David Victorson, $\mathrm{PhD}^{1,2}$ Christina Luberto, $\mathrm{PhD}_{1}^{3,4}$ and Karen Koffler, $\mathrm{MD}^{5}$
}

Editor's Note: Debate over the evidence supporting integrative care interventions not infrequently references the challenges funding research on natural agents and practices that are not patentable. The subject of this column goes to the mother of all such interventions, nature herself. Yet in this case, the authors report an awakening of research that affirms nature's power in health and well-being. This is the eighth commentary through JACM's column partnership with the Osher Collaborative for Integrative Medicine through which we seek to stimulate critical conversations via perspectives from the leaders of the Collaborative's seven prominent academically based integrative centers. The author team came together from three of the centers: David Victorson, PhD, at the Northwestern University Feinberg School of Medicine, Christina Luberto, PhD, at the Harvard Medical School, and Karen Koffler, MD, at the University of Miami Miller School of Medicine. While providing readers an understanding of how to examine nature as medicine, they propose a "goodness of fit" between the precepts of the integrative field and the natural world.-Editor-in-Chief, John Weeks (johnweeks-integrator.com)

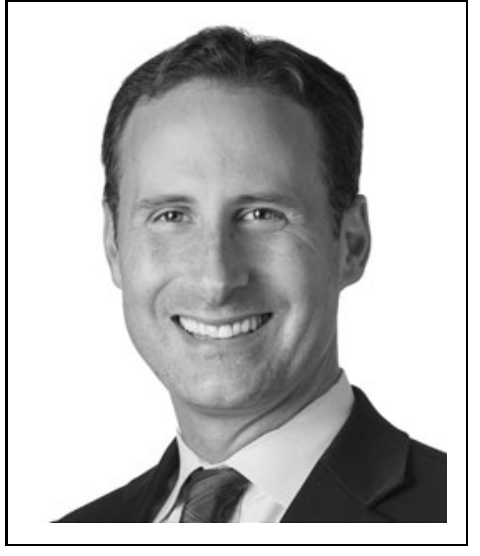

David Victorson, PhD

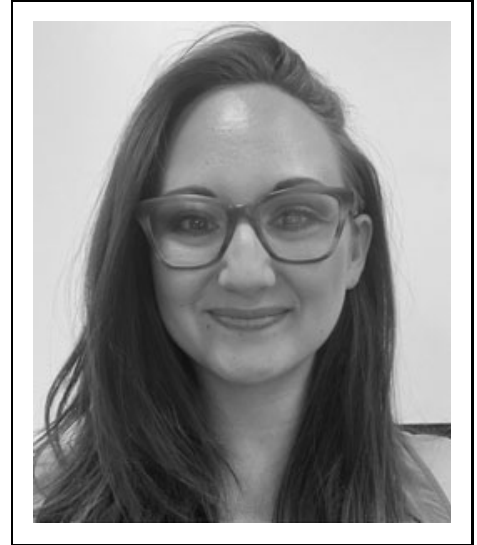

Christina Luberto, PhD

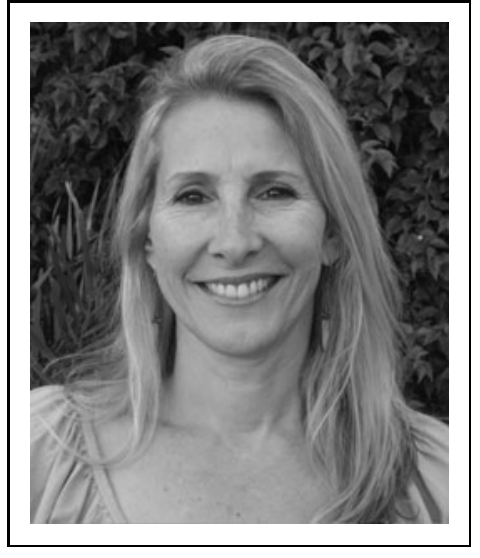

Karen Koffler, MD

\section{Introduction}

$\mathbf{O}$ VER THE PAST SEVERAL DECADES, increasing attention across multiple disciplines has focused on the positive relationship between connecting with nature and improvements in human health. A common focus has been evaluating phenomena most people "naturally" understand to be true by way of being human: purposefully spending time in nature can be inherently good for us-mind, body, and soil. Nature contact confers a host of health benefits spanning cognitive, emotional, social, physical, and biophysiologic domains. ${ }^{1}$ It may even foster certain "ecologic sensibilities" that prompt us to safeguard the well-being of Mother Earth herself. ${ }^{2}$ Given the intersection between conventional health outcomes

\footnotetext{
${ }^{1}$ Department of Medical Social Sciences, Feinberg School of Medicine, Northwestern University, Chicago, IL, USA.

${ }^{2}$ Osher Center for Integrative Medicine, Northwestern University, Chicago, IL, USA.

${ }^{3}$ Department of Psychiatry, Massachusetts General Hospital, Harvard Medical School, Boston, MA, USA.

${ }^{4}$ Osher Center for Integrative Medicine, Brigham and Women's Hospital, Harvard Medical School, Boston, MA, USA.

${ }^{5}$ Osher Center for Integrative Medicine, Miller School of Medicine, University of Miami, Miami, FL, USA.
} 
and the purported therapeutic basis of nature contact, what role, if any, does the field of complementary and integrative health $(\mathrm{CIH})$ have in studying and promoting nature as medicine?

Herein we posit the strong goodness-of-fit between these two areas that could help advance rigorous scientific inquiry, public policy and discourse, and evidence-based applications. CIH practitioners, researchers, and professional associations are ideally suited for this. We are accustomed to applying modern scientific methods to therapeutic practices based on ancient healing systems to determine if they are safe, tolerable, efficacious, and add real-world value to health and well-being. A fit also exists relative to shared challenges. A new wave of $\mathrm{CIH}$ research and policy is focusing on issues of health equity, access, and implementation science to eliminate disparities in who gets to benefit from CIH. While nature contact is seemingly "free," similar inequities exist across racial, educational, and other socioeconomic factors. ${ }^{3}$ This is problematic, as green space is more than just something nice to look at. In addition to documented human health benefits, green space can also influence the health of our planet. ${ }^{4}$

In this study, we provide a working understanding of nature as medicine and briefly review some of the evidencebased health benefits that have been documented. We then review the status of nature as medicine within current $\mathrm{CIH}$ targets. This includes National Institutes of Health (NIH) grants awarded, journal publications, special interest groups, and other educational and policy-relevant offerings. Finally, we offer some closing remarks and recommendations.

\section{Nature As Medicine: Ancestral Roots, Theoretical Underpinnings, and Personal Connections}

One of the authors grew up hearing their grandmother recite a poem she wrote following the tragic death of her firstborn son. He was killed in a car accident at the age of 22 years while coming home to visit her for Mother's Day while on leave from the military. She was so despondent after his death she could not sleep or eat for some time. Her husband finally did the only thing he knew that might help her. He drove her out into the forest to a place where they picked wild blueberries. He helped her find a log to sit on and then let her be. This is where she wrote the poem "Forest Cathedral,", which embodies her transformative experience in the woods that day. This poem has served as an ancestral touchstone within her descendants' collective consciousness that purposeful contact with nature, especially during trying times, can be healing and restorative.

Oh how I love to walk out in the woods

In its calm and still beauty I have long understood

As I look at the wonders our creator has made

All the hustle and bustle of this world seems to fade

Down in the meadow you hear the call of a lark

While high on the hill some deer feed on bark

There are wintergreen berries and wild onion shoots

An abundance of flowers and trailing green roots

Now if you go in the forest with the world you're off key

And you're quiet and still and you sit and you see

Here you know of God's love and you know by God's grace

Of all worldly issues you're able to face

- "Forest Cathedral," 1956
This folk appreciation of nature is not unique. The medicinal nature of nature has been largely understood through personal experiences and the historical prism of ancestral traditions and civilizations. This includes ancient Egyptians, Chinese, Persians, Indians, and First Nation and indigenous peoples around the world. ${ }^{5}$ The idea that nature contact can affect our health stems back to Hippocrates' treatise Airs, Waters, and Places. ${ }^{6}$ Throughout millennia, ancient societies left signs and cultural artifacts that highlighted the vast interconnectedness and interdependence they had with nature for health, healing, sustainability, survival, and spiritual affiliation. ${ }^{5}$ Connecting with nature for the transactional sake of health benefit is largely a modern pursuit that is similar to what has happened with the Westernization of traditions such as yoga or meditation. Magazine covers depicting the health benefits of nature in grocery store checkout lines have already begun to rival those of calm and happy people meditating or practicing yoga. This is in contradistinction with a more traditional wisdom that nature is merely an extension of one's body, mind, spirit, lifestyle, and ethical values.

It is also hypothesized that humans may be wired with an innate affinity for meaningful contact with nature, no different from our innate fear of potential harms found in the natural world. The notion of biophilia ${ }^{7,8}$ suggests that humans have a genetic predisposition to be attracted to certain features in nature that were once associated with our survival. Examples include bodies of water where one could drink, encounter wildlife to hunt, or use to escape danger on watercraft; forest habitats where trees could be climbed to evade predators, or hunting and gathering could occur; and vast open spaces and mountaintops that could offer visual openness to see oncoming food or threats.

Other theories involve cognitive and affective pathways. The Stress Recovery Theory 9 posits that contact with nature increases positive emotion, which relieves physiologic stress. The Attention Restoration Theory ${ }^{10}$ suggests that exposure to nature reduces mental fatigue. As a result, other positive experiences may emerge. Some evidence suggests that both may independently complement one another. ${ }^{11}$

\section{The Nature of Nature: A Working Understanding}

The word "nature" itself can be challenging to operationalize. Terms such as "green space or blue space" can also be limited given the extensive color palette represented in different outdoor settings. In this study, we have adopted (and adapted-our additions are in brackets) a working understanding of nature set forth by Maller et al. ${ }^{12}$ as follows:

1. "an organic [outdoor] environment [occurring either naturally or with human assistance], where the majority of ecosystem processes are present (e.g., birth, death, reproduction, relationships between species)', [which might include]:

2. "the spectrum of habitats and wilderness areas [(e.g., forests, mountains, prairies, deserts, oceans, rivers, streams, ponds, lakes), atmospheric and celestial phenomena (e.g., clouds, sky, rain and snow, sunlight, stars, sunsets/sunrises, rainbows, Northern lights, aromatic chemicals, microbes), urban preserves, woodlands, parks, and neighborhood vegetation and horticulture"'] 
and ["personal or community] gardens, and [yards"; and one that:]

3. "refers to any single element of the natural environment... [or a combination thereof.']

Other associations, such as benefits of animal contact or harvesting and consuming food and other materials through farming, hunting, and fishing, are beyond the scope of this study.

Frumkin et al. ${ }^{13}$ eloquently described the matrix of pathways by which humans may encounter nature. This includes (1) spatial scale (e.g., potted plant or window view [Small scale]; gardening or walking in a nearby forest preserve [Medium scale]; spending multiple nights in a wilderness setting [Large scale]; (2) proximity (e.g., how close/far or embedded is it within one's normal surroundings); (3) frequency of contact (e.g., is the encounter occasional, recurring, or routine/ongoing); (4) activities one engages in (e.g., sedentary vs. movement-based); (5) level of awareness (e.g., is nature itself the object of one's attention, or merely a place where one looks at a phone); and the (6) sensory pathways in which nature is experienced (e.g., visual, auditory, tactile, olfactory, gustatory). It should become common practice to describe these different dimensions and their potential effects in future nature as medicine research.

\section{Nature As a Major Health Determinant for Humans and the Planet}

Interacting with certain aspects of nature can be unsafe, fear inducing, and even deadly (from ultraviolet radiation exposure and dangerous wildlife to natural disasters, environmental toxins, being homeless, or living in a violent neighborhood). Other forms of nature contact are major health determinants, ${ }^{14}$ akin to staying hydrated, getting enough steps, or clocking sufficient hours of sleep at night. From this perspective, encountering, observing, and connecting with nature can be a positive health behavior in and of itself.

Despite varying qualities of study designs and levels of empirical support, an extensive body of evidence suggests nature's role in improving multiple domains of human health. This includes reduction of stress, anxiety, depression, and increased positive affect and well-being. ${ }^{15,16}$ Other studies have documented improved sleep, ${ }^{17}$ cognition, ${ }^{18}$ pain control, ${ }^{19}$ social connectedness, ${ }^{20}$ physical activity, ${ }^{21}$ cardiovascular outcomes, ${ }^{22}$ immune system functioning, ${ }^{14}$ and increased regard for the environment. ${ }^{23}$

For some of these benefits (e.g., increased physical activity, social cohesion, and proenvironmental stewardship), nature may serve as a holding environment by which these expressions are nurtured and manifested, creating a positive feedback loop. We often narrowly limit the scope of nature's health benefits to humans only; however, this evidence suggests that the health of the planet also has much to gain. Please see Appendix A1.

\section{The Status of Nature As Medicine Within CIH}

Currently, there are nascent indications that academic $\mathrm{CIH}$ programs, professional associations, academic journals, and $\mathrm{CIH}$-aligned funding agencies are starting to value nature as medicine initiatives. We conducted a nonsystematic scoping keyword search (using terms such as "green space," "blue space," "forest'” or "nature", with "health") for funded NIH grants (using NIH RePORT), and searched peer-reviewed publications in major $\mathrm{CIH}$ journals, and other academic $\mathrm{CIH}$ offerings (invited lectures, symposia, special interest groups, etc.). At the time of this publication, there were no currently funded research studies from the National Center for Complementary and Integrative Health (NCCIH) that explicitly focused on relationships between nature and health. However, of the 29 funded grants that included the keyword "green space," six appeared to have some focus on the impact of green space on health (Table 1). Two were funded by the National Cancer Institute, two by the National Institute for Environmental Health Sciences, and two by the National Heart, Lung, and Blood Institute.

In our search of major $\mathrm{CIH}$ journals, we identified 17 publications between 2004 and 2019 that focused on nature and health in some way (Table 2). In comparison, a PubMed search of "green space" and "health" yielded 630 publications between 1994 and 2020, while a search of "forest bathing" alone yielded 41 publications between 2006 and 2020. Most of these were found in environmental health research journals.

In 2018, the NCCIH hosted a webcast lecture on the current state of the field of research on nature and mental health. ${ }^{24}$ The 2020 International Congress for Integrative Medicine and Health's Biannual Meeting accepted a "Hot Topic" Symposium entitled, "Eco-Wellness: Connection, Health, and Preservation of Mind, Body, and Soil." 25 Also, in 2020, the Academic Consortium for Integrative Medicine and Health started a Special Interest Group dedicated to Nature and Health.

Finally, previous leaders from the Bravewell Collaborative cofounded The Healthy US Collaborative, which recently launched a national campaign called TakeCare. This

TAble 1. Identified National Institutes of Health-Funded Grants Focusing in Some Way on Green Space and Health

\begin{tabular}{|c|c|c|c|}
\hline Project title & Institute & $\begin{array}{c}\text { Type of } \\
\text { grant }\end{array}$ & $\begin{array}{l}\text { Start } \\
\text { year }\end{array}$ \\
\hline $\begin{array}{l}\text { Urban greenness and } \\
\text { cardiovascular health }\end{array}$ & NIEHS & R01 & 2018 \\
\hline $\begin{array}{l}\text { Do innovative playgrounds } \\
\text { mitigate health disparities }\end{array}$ & NHLBI & R01 & 2019 \\
\hline $\begin{array}{l}\text { Impact of park renovations on } \\
\text { physical activity and } \\
\text { community health in NYC }\end{array}$ & $\mathrm{NCI}$ & R01 & 2016 \\
\hline $\begin{array}{l}\text { Deep learning of street view } \\
\text { imagery to assess urban green } \\
\text { space relationships with mental } \\
\text { health: A twin study }\end{array}$ & NIEHS & R21 & 2019 \\
\hline $\begin{array}{l}\text { Impact of ecological park } \\
\text { restoration on health in low } \\
\text { income neighborhoods: A } \\
\text { natural experiment }\end{array}$ & $\mathrm{NCI}$ & R01 & 2019 \\
\hline $\begin{array}{l}\text { Associations of neighborhood } \\
\text { green space and social } \\
\text { disadvantage with stress- } \\
\text { sensitive inflammatory } \\
\text { biomarkers }\end{array}$ & NHLBI & F31 & 2019 \\
\hline
\end{tabular}

NCI, National Cancer Institute; NHLBI, National Heart, Lung, and Blood Institute; NIEHS, National Institute for Environmental Health Sciences. 
Table 2. Peer-Reviewed Publications Focusing on Green Space, Blue Space, or Nature and Health IDENTIFIED In COMPLEMENTARY AND INTEGRATIVE Health Journals

\begin{tabular}{|c|c|c|}
\hline Author & Title & Journal \\
\hline Schweitzer et al. & $\begin{array}{l}\text { Healing spaces: Elements of environmental design that make } \\
\text { an impact on health }\end{array}$ & JACM (2004), 10(1), S71-S83 \\
\hline Oschman & Our place in nature: reconnecting with the Earth for better sleep & JACM (2004), 10(5), 735-736 \\
\hline Benda & Nature's child & JACM $(2008), 14(10), 1177$ \\
\hline Benda & Flower power & JACM (2009), 15(9), 951-952 \\
\hline Coulter & Healing gardens: When nature is the therapy & ACT (2009), 5(2), published online \\
\hline Tripoli & $\begin{array}{l}\text { Ecopsychology: Mind, body, spirit....and planet: An interview } \\
\text { with Thomas Joseph Doherty }\end{array}$ & ACT (2009), 15(6), published online \\
\hline Oschman & Our place in nature: Reconnecting with the earth & JACM (2010), 16(3), 225-226 \\
\hline Lechtizn et al. & $\begin{array}{l}\text { A randomized trial of nature scenery and sounds versus urban } \\
\text { scenery and sounds to reduce pain in adults undergoing bone } \\
\text { marrow aspirate and biopsy }\end{array}$ & JACM (2010), 16(9), 965-972 \\
\hline Baldwin & How do plants in hospital waiting rooms reduce patient stress? & JACM (2012), 18(4), 309-310 \\
\hline Beukeboom et al. & $\begin{array}{l}\text { Stress-reducing effects of real and artificial nature in a hospital } \\
\text { waiting room }\end{array}$ & JACM (2012), 18(4), 329-333 \\
\hline Horowitz & $\begin{array}{l}\text { Therapeutic gardens and horticultural therapy: Growing roles } \\
\text { in health care }\end{array}$ & ACT (2012), 18(2), published online \\
\hline Mantler et al. & Natural environments and mental health & AIM $(2015$ \\
\hline Alter et al. & $\begin{array}{l}\text { Nature cure treatment in the context of India's epidemiological } \\
\text { transition }\end{array}$ & JIM (2016), 14(4), 245-254 \\
\hline Hansen & Rx: Walk in the forest: Shinrin'Yoku's holistic healing effects & JACM (2018), 24(8), 745-747 \\
\hline Hart & Blue space: How being near water benefits health & ACT (2019), 25(4), published online \\
\hline Payne et al. & $\begin{array}{l}\text { The most natural of natural therapies: A review of the health } \\
\text { benefits derived from Shinrin-Yoku (Forest Bathing) }\end{array}$ & AIM (2019), 6(S1), S109-S110 \\
\hline La Puma & Nature therapy: An essential prescription for health & ACT (2019) 25(2), published online \\
\hline
\end{tabular}

ACT, Alternative and Complementary Therapies; AIM, Advances in Integrative Medicine; JACM, The Journal of Alternative and Complementary Medicine; JIM, Journal of Integrative Medicine.

initiative created over 40 short films addressing whole health — mind, body, spirit, and community. One of the films was entitled "Nature: No App Required."

\section{Conclusion}

At no other time in human history have we been so disconnected from the natural world. Yet, we are also probably the most connected we have ever been to scientific discoveries on how nature contact can benefit our health. Irony is not lost that this growing evidence base shares parallel trajectories with the ever-increasing oceanic temperatures, disappearing natural habitats, and increasing numbers of pollutants in the air we breathe and water we drink.

The field of CIH has a special opportunity and responsibility to engage in this science; to share and apply the collective wisdom and lessons learned that have been acquired through rigorous study of other similar ancient healing systems and traditions. Doing so will naturally encourage team science and broaden the $\mathrm{CIH}$ tent to other disciplines. The NCCIH specifically has an important role in facilitating this. Their new 5-year strategic plan to consider whole person health and whole health systems ${ }^{25}$ sets the stage for nature as medicine to be included in the lineup. This inclusion will contribute to the formulation of important questions around nature and health. It will help establish a national research agenda and priorities, and make research funding possible to support CIH-relevant initiatives involving nature. $\mathrm{CIH}$ professional associations are taking positive steps to seed nature as medicine programming within the curricula and create sustainability through special interest groups. The fruits of these activities will only continue to blossom. With growing requests for grant applications, $\mathrm{CIH}$ journals will no doubt receive increasing numbers of high-quality submissions on different topics related to nature and health. In addition, journals can take a more active role by supporting special issues on nature as medicine. By adopting these big picture actions, we can help own and advance this science so that our patients, our communities, and our planet can flourish.

\section{Author Disclosure Statement}

No competing financial interests exist.

\section{Funding Information}

This article was funded by the National Center for Complementary and Integrative Health (AT00915).

\section{References}

1. Seymour V. The human-nature relationship and its impact on health: A critical review. Front Public Health 2016;4:260.

2. Hansen-Ketchum P, Marck P, Reutter L. Engaging with nature to promote health: New directions for nursing research. J Adv Nurs 2009;65:1527-1538.

3. Nesbitt L, Meitner MJ, Girling C, et al. Who has access to urban vegetation? A spatial analysis of distributional green equity in 10 US cities. Landscape Urban Plann 2019;181:51-79.

4. Sobstyl JM, Emig T, Qomi MJA, et al. Role of City Texture in Urban Heat Islands at Nighttime. Phys Rev Lett 2018; 120:108701.

5. Coates PA. Nature: Western Attitudes Since Ancient Times. Berkeley: University of California Press, 1998. 
6. Wear A. Place, health, and disease: The airs, waters, places tradition in early modern England and North America. J Med Early Modern Stud 2008;38:443-465.

7. Kellert SR, Wilson EO. The Biophilia Hypothesis. Washington, DC: Island Press, 1993.

8. Wilson EO. Biophilia. Cambridge, MA: Harvard University Press, 1984.

9. Ulrich RS, Simons RF, Losito BD, et al. Stress recovery during exposure to natural and urban environments. J Environ Psychol 1991;11:201-230.

10. Kaplan S. The restorative benefits of nature: Toward an integrative framework. J Environ Psychol 1995;15:169-182.

11. Li D, Sullivan WC. Impact of views to school landscapes on recovery from stress and mental fatigue. Landscape Urban Plan 2016;148:149-158.

12. Maller C, Townsend M, Pryor A, et al. Healthy nature healthy people: 'contact with nature' as an upstream health promotion intervention for populations. Health Promot Int 2006;21:45-54.

13. Frumkin H, Bratman GN, Breslow SJ, et al. Nature contact and human health: A research agenda. Environ Health Perspect 2017;125:075001.

14. Kuo M. How might contact with nature promote human health? Promising mechanisms and a possible central pathway. Front Psychol 2015;6:1093.

15. Bratman GN, Anderson CB, Berman MG, et al. Nature and mental health: An ecosystem service perspective. Sci Adv 2019;5:eaax0903.

16. Houlden V, Weich S, Porto de Albuquerque J, et al. The relationship between greenspace and the mental wellbeing of adults: A systematic review. PLoS One 2018;13:e0203000.

17. Grigsby-Toussaint DS, Turi KN, Krupa M, et al. Sleep insufficiency and the natural environment: Results from the US Behavioral Risk Factor Surveillance System survey. Prev Med 2015;78:78-84.

18. Bratman GN, Hamilton JP, Daily GC. The impacts of nature experience on human cognitive function and mental health. Ann N Y Acad Sci 2012;1249:118-136.

19. Han JW, Choi H, Jeon YH, et al. The effects of forest therapy on coping with chronic widespread pain: Physio- logical and psychological differences between participants in a forest therapy program and a control group. Int J Environ Res Public Health 2016;13:255.

20. Jennings V, Bamkole O. The relationship between social cohesion and urban green space: An avenue for health promotion. Int J Environ Res Public Health 2019;16:452.

21. Hunter RF, Christian H, Veitch J, et al. The impact of interventions to promote physical activity in urban green space: A systematic review and recommendations for future research. Soc Sci Med 2015;124:246-256.

22. Twohig-Bennett $\mathrm{C}$, Jones A. The health benefits of the great outdoors: A systematic review and meta-analysis of greenspace exposure and health outcomes. Environ Res 2018;166:628-637.

23. Rosa CD, Collado S. Experiences in nature and environmental attitudes and behaviors: Setting the ground for future research. Front Psychol 2019;10:763.

24. Bratman GN. Nature contact and human health: A multimethod approach. NCCIH Integrative Medicine Research Lecture Series. 2018. Online document at: https://videocast .nih.gov/Summary.asp?Live $=28440 \&$ bhcp $=1$, accessed April 29, 2020.

25. Langevin $\mathrm{H}$. Considering whole person health as we develop NCCIH's next strategic plan. NCCIH Messages from the Director. 2020, Online document at: https://www .nccih.nih.gov/about/offices/od/director/past-messages/ considering-whole-person-health-as-we-develop-nccihsnext-strategic-plan, accessed April 29, 2020.

Address correspondence to: David Victorson, PhD Department of Medical Social Sciences Feinberg School of Medicine Northwestern University Chicago, IL, 60611 USA

E-mail: d-victorson@northwestern.edu

\section{Appendix A1. Potential Questions for a Nature-Research Agenda in Complementary-Integrative Health}

- Why does spending time in nature make people feel good?

- How can we best include the perspectives and wisdom of indigenous peoples and ancestral traditions when establishing a research agenda?

- Is it simply a hedonic effect, or does eudemonia play a role when things such as awe, fascination, gratitude, and a sense of wonder come into play?

- What if you do not like being outside in green or blue spaces? Do you still derive a health benefit?

- Do healthier people just self-select into "greener" neighborhoods?

- Does culture, personality, and previous life experiences play a role?

- Does being in nature induce greater mindful awareness?
- Do we need to direct effortful attention to nature or can we derive the same health benefits if we are talking to others or absorbed in our phones while in green space?

- How does nature get under our skin and innervate complex biophysiologic regulatory processes?

- To what extent does nature lead to other positive health behaviors?

- How much nature contact do we actually need to benefit in a meaningful way?

- Do certain types of nature contact lead to greater benefits?

- What role, if any, does environmental chemicals, biologic agents, and biodiversity play (e.g., phytoncides, negative air ions, mycobacterium vaccae)?

- Can technology be used to increase our understanding and application? 